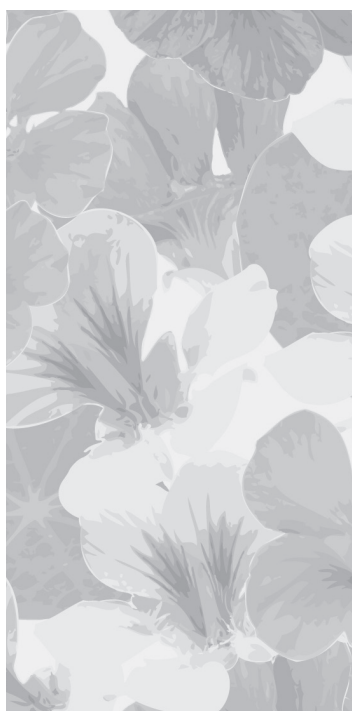

\title{
Marketing internetowy usług z zakresu medycyny estetycznej, dermatologii estetycznej oraz chirurgii estetycznej
}

\author{
Internet marketing of services in the field of aesthetic medicine, aesthetic \\ dermatology and aesthetic surgery
}

Agnieszka Zabiegała, Radosław Śpiewak

Zakład Dermatologii Doświadczalnej i Kosmetologii, Wydział Farmaceutyczny Uniwersytet Jagielloński Collegium Medicum, Kraków

Estetol Med Kosmetol 2012; 2(1): 24-27

DOI: http://dx.doi.org/10.14320/EMK.2012.005

\section{Streszczenie}

Stosowanie przez placówki medyczne zachowań marketingowych służących pozyskaniu klientów-pacjentów jest ograniczone Ustawą o zawodach lekarza i lekarza dentysty, Ustawą o izbach lekarskich, Uchwałą Naczelnej Rady Lekarskiej oraz Kodeksem etyki lekarskiej. Celem niniejszego artykułu było zbadanie i opisanie sposobów promocji w Internecie placówek oferujących zabiegi z zakresu szeroko pojętej medycyny estetycznej w porównaniu do „tradycyjnych” specjalności lekarskich. Materiat i metody: Do analizy włączyliśmy 170 stron internetowych placówek medycznych (poradnie, gabinety lub praktyki lekarskie) oferujących usługi z zakresu medycyny estetycznej, dermatologii estetycznej lub chirurgii estetycznej oraz 300 internetowych stron placówek alergologicznych, ginekologicznych oraz kardiologicznych. Strony internetowe placówek przeanalizowaliśmy pod kątem występowania treści charakterystycznych dla działań marketingowych. Wyniki: Na stronach internetowych 98\% placówek z zakresu szeroko pojętej medycyny estetycznej zidentyfikowaliśmy co najmniej jedną niedozwoloną strategię marketingową. Najczęściej byto to podawanie nazw handlowych stosowanych preparatów (80-91\%), a w dalszej kolejności podawanie marek stosowanego sprzętu (70-86\%), zachwalanie skuteczności stosowanych preparatów i metod (54-80\%) lub sprzętu (51-78\%), obietnice/gwarancje bezpieczeństwa i braku działań niepożądanych (24-59\%), oferowanie promocyjnych cen i pakietów cenowych na zabiegi (53-56\%), reklamowanie gabinetu na Facebooku, Twitterze, Google+ (31-55\%), gwarantowanie efektu (23-51\%), obiecywanie efektów wykraczających poza faktyczny efekt biologiczny zabiegu (20-43\%) oraz siedem innych, rzadziej stosowanych technik marketingowych. Zaledwie 6\% stron internetowych placówek alergologicznych, ginekologicznych oraz kardiologicznych zawierało niedozwolone treści marketingowe, najcześciej zachwalanie lekarzy. Wnioski: Prawie wszystkie placówki oferujące usługi z zakresu medycyny estetycznej, a tylko nieliczne placówki z zakresu „tradycyjnych” specjalności lekarskich stosują praktyki marketingowe niezgodne z duchem lekarskiej etyki zawodowej oraz obowiązującego prawa.

Stowa kluczowe: marketing, reklama, usługi medyczne, estetologia medyczna, medycyna estetyczna, dermatologia estetyczna, chirurgia estetyczna, metody promocji, alergologia, ginekologia, kardiologia, Internet, regulacje prawne

\begin{abstract}
The use of marketing strategies aimed at attracting more patients/customers by Polish doctors and medical companies is limited by the Physician's and Dentist's Profession Act, the Act on Chambers of Physicians, resolutions of the Supreme Medical Council, and the Code of Medical Ethics. The aim of this article was to analyse strategies of promotion on the Internet utilized by medical facilities that offer procedures from the broad field of aesthetic medicine, compared with 'traditional' medical specialties. Material and methods: We included into the present analysis 170 websites of medical facilities (clinics, consultancies, medical practices) offering services from the field of aesthetic medicine, aesthetic dermatology and aesthetic surgery, as well as 300 websites of medical facilities in the field of allergology, gynaecology and cardiology. The websites were searched for the occurrence of contents characteristic of marketing. Results: Websites of $98 \%$ of the facilities for aesthetic medicine contained at least one marketing strategy prohibited by the law or codes of ethics. The most common marketing strategy was announcing trade names of products used in treatments (80-91\% depending on the type of facility), announcing brand names of equipment used (70-86\%), touting the alleged effectiveness of products and methods in use (54-80\%) or equipment (51-78\%), promising/guaranteeing the safety and lack of side-effects (24-59\%), offering discounts or price packages (53-56\%), advertising on Facebook, Twitter, Google+ (31-55\%), guaranteeing effects of treatments (23-51\%), promising effects beyond the actual biological effect of a treatment (20-43\%), and seven other, less frequent marketing techniques. Only $6 \%$ websites of allergy, gynaecology or cardiology facilities contained prohibited marketing content, in most cases touting the doctors. Conclusions: Almost all medical facilities offering services of aesthetic medicine, but only a few facilities of 'traditional' medical specialties, use marketing practices prohibited by the medical professional codes of ethics and the legislation in force.
\end{abstract}

Keywords: marketing, advertisement, medical services, medical aesthetology, aesthetic medicine, aesthetic dermatology, aesthetic surgery, methods of promotion, allergology, gynecology, cardiology, Internet, legal regulations

Copyright @ 2012 the Authors (text) and Radosław Śpiewak (layout \& journal compilation). All rights reserved.

Na rynku medycznym pojawia się coraz więcej placówek oferujących usługi z zakresu medycyny estetycznej, dermatologii estetycznej lub chirurgii estetycznej. Narastająca konkurencja wymusza podejmowanie aktywnych działań marketingowych mających na celu pozyskanie klienta-pacjenta. Jednak stosowanie reklam przez placówki medyczne jest ograniczone Ustawą o zawodach lekarza i lekarza dentysty [1], Ustawą 
o izbach lekarskich [2], uchwałą Naczelnej Rady Lekarskiej [3] oraz Kodeksem etyki lekarskiej [4].

\section{Cel}

Celem niniejszej pracy było zbadanie i opisanie sposobów promocji w Internecie usług placówek oferujących zabiegi z zakresu medycyny estetycznej, dermatologii estetycznej lub chirurgii estetycznej w porównaniu do „tradycyjnych” specjalności lekarskich.

\section{Materiat i metody}

Przedstawione analizy przeprowadziliśmy między wrześniem 2011 roku a marcem 2012 roku. Do analizy włączyliśmy strony internetowe 100 placówek medycznych (poradnie, gabinety, praktyki lekarskie) oferujących usługi z zakresu medycyny estetycznej, oraz 70 placówek oferujących usługi z zakresu dermatologii estetycznej lub chirurgii estetycznej. Za placówki medycyny estetycznej uznawaliśmy ośrodki, których strony internetowe w opisie działalności zawierały wyłącznie termin „medycyna estetyczna”. Za placówki dermatologii estetycznej oraz chirurgii estetycznej uznawaliśmy takie, których internetowy opis działalności zawierał odpowiednio terminy „dermatologia estetyczna” lub „chirurgia estetyczna” wyłącznie lub w kombinacji z terminem „medycyna estetyczna”. W celach porównawczych analogicznej analizie poddaliśmy strony internetowe 300 placówek medycznych oferujących usługi z zakresu „tradycyjnych” specjalności lekarskich - alergologii, ginekologii oraz kardiologii (po 100 stron dla każdej specjalności). Treści stron internetowych przeanalizowaliśmy pod kątem występowania cech charakterystycznych dla reklamy wymienionych $\mathrm{w}$ tabeli 1. Analizę stron internetowych zawęziliśmy do treści jawnej, to znaczy do tekstu wyświetlanego na ekranie komputera, ze szczególnym uwzględnieniem strony powitalnej oraz stron opisujących profil działalności i ofertę placówki. W analizie nie braliśmy pod uwagę niewidocznych słów kluczowych ukrytych w kodzie źródłowym, a także reklam i linków do innych stron. Różnice w częstości stosowania poszczególnych niedozwolonych praktyk oceniono statystycznie za pomocą testu chi-kwadrat. W celu uzyskania maksymalnej porównywalności analizowanych danych, placówki medyczne zostały przyporządkowane do dwóch grup: (1) placówki z zakresu medycyny estetycznej, dermatologii estetycznej i chirurgii estetycznej oraz (2) placówki z zakresu alergologii, ginekologii i kardiologii.

\section{Wyniki}

Szczegółowe wyniki analiz przedstawia tabela 1. Najczęściej stosowaną strategią marketingową przez placówki z zakresu medycyny estetycznej, dermatologii lub chirurgii estetycznej było podawanie nazw handlo- wych preparatów stosowanych w czasie zabiegów, co nie było praktykowane przez placówki z zakresu alergologii, ginekologii oraz kardiologii. Ponad połowa analizowanych placówek z zakresu szeroko pojętej medycyny estetycznej oferowała na swoich stronach internetowych promocyjne ceny lub pakiety na zabiegi (dodatkowe usługi gratis lub rabaty w przypadku skorzystania z dodatkowych usług). Interesującym, choć rzadko spotykanym sposobem reklamy stosowanym wyłącznie przez placówki medyczne oferujące usługi z zakresu medycyny estetycznej było korzystanie z rekomendacji celebrytów jako klientów danej placówki.

\section{Dyskusja}

W literaturze fachowej [5] poświęconej marketingowi w opiece zdrowotnej, słowo „marketing” definiuje się, jako proces planowania oraz wdrażania koncepcji produktu, polityki cenowej oraz sposobu promocji. „Promocja" definiowana jest jako mieszanka strategii marketingowych, która jest stosowana przez organizacje w celu informowania konsumentów o swoich produktach i ich cenach oraz wywarcia wpływu na konsumentów, aby kupili dany produkt [5]. Natomiast pojęcie „reklama” oznacza wykorzystanie różnych mediów w celu zwrócenia uwagi potencjalnych lub dotychczasowych klientów na określony produkt lub usługę [5]. Pomimo istnienia literatury poświęconej zagadnieniu efektywnego marketingu w polskiej służbie zdrowia, w tym skutecznego przyciągania nowych klientów - pacjentów do placówki [6-9], w świetle obowiązującego Kodeksu etyki lekarskiej, Ustawy o zawodach lekarza i lekarza dentysty oraz Ustawy o izbach lekarskich lekarz nie może reklamować swoich usług $[1,2,4]$. Na podstawie przeprowadzonych badań widzimy jednak, że zdecydowana większość placówek szeroko rozumianej medycyny estetycznej stosuje praktyki marketingowe niezgodne $\mathrm{z}$ duchem tych regulacji, w przeciwieństwie do placówek oferujących usługi medyczne z zakresu „tradycyjnych” specjalności - alergologii, ginekologii oraz kardiologii. Zwraca też uwagę stosowanie przez $8-16 \%$ analizowanych placówek oferujących usługi z medycyny estetycznej oraz dermatologii estetycznej i chirurgii estetycznej oznaczenia „klinika”. Ustawa o zakładach opieki zdrowotnej ogranicza prawo do stosowania terminu „klinika” wyłącznie do placówek utworzonych i utrzymywanych w celu prowadzenia badań naukowych i prac badawczo-rozwojowych lub realizacji zadań dydaktycznych i badawczych w powiązaniu z udzielaniem świadczeń zdrowotnych i promocją zdrowia [10]. Interesującym, choć niezbyt częstym zjawiskiem jest powoływanie się na celebrytów jako osoby korzystające z usług danej placówki medycyny estetycznej. Firmy chcące zareklamować swoje produkty coraz częściej wykorzystują popularność celebrytów, a zjawisko to doczekało się nawet swojego określenia Celebrity Worship Syndrome, czyli syndrom uwielbienia 
Tabela 1. Analiza technik marketingowych stosowanych na stronach internetowych placówek medycyny estetycznej, dermatologii estetycznej oraz chirurgii estetycznej, alergologii, kardiologii oraz ginekologii

\begin{tabular}{|c|c|c|c|c|c|c|c|}
\hline Opis strategii marketingowej & Przyklad & $\begin{array}{l}\text { Liczba (\%) } \\
\text { placówek } \\
\text { medycyny } \\
\text { estetycznej } \\
{[\mathrm{N}=100]}\end{array}$ & $\begin{array}{l}\text { Liczba }(\%) \\
\text { placówek } \\
\text { dermatologii } \\
\text { estetycznej } \\
\text { lub chirurgii } \\
\text { estetycznej } \\
{[\mathrm{N}=70]}\end{array}$ & $\begin{array}{l}\text { Liczba }(\%) \\
\text { placówek } \\
\text { alergologii } \\
{[\mathrm{N}=100]}\end{array}$ & $\begin{array}{l}\text { Liczba }(\%) \\
\text { placówek } \\
\text { ginekologii } \\
{[\mathrm{N}=100]}\end{array}$ & $\begin{array}{l}\text { Liczba }(\%) \\
\text { placówek } \\
\text { kardiologii } \\
{[\mathrm{N}=100]}\end{array}$ & $\begin{array}{l}\text { P dla } \\
\text { różnicy w } \\
\text { odsetkach^ } \\
\text { (test chi- } \\
\text { kwadrat) }\end{array}$ \\
\hline $\begin{array}{l}\text { Stosowanie przynajmniej jednej } \\
\text { strategii marketingowej }\end{array}$ & (patrz niżej) & $100(100 \%)$ & $67(96 \%)$ & $8(8 \%)$ & $6(6 \%)$ & $4(4 \%)$ & $<0,001$ \\
\hline $\begin{array}{l}\text { Podawanie nazw handlowych } \\
\text { preparatów stosowanych } \\
\text { w zabiegach }\end{array}$ & „BOTOX®", „Voluma $\mathbb{}$ & $91(91 \%)$ & $56(80 \%)$ & $2(2 \%)$ & 0 & 0 & $<0,001 *$ \\
\hline $\begin{array}{l}\text { Podawanie marek stosowanych } \\
\text { urządzeń }\end{array}$ & „Thermage $\mathbb{Q} ",$, ,Titan $\mathbb{R} "$ & $86(86 \%)$ & $49(70 \%)$ & 0 & 0 & 0 & $<0,001^{*}$ \\
\hline $\begin{array}{l}\text { Zachwalanie skuteczności } \\
\text { preparatów i metod }\end{array}$ & „najskuteczniejsze usuwanie owłosienia” & $80(80 \%)$ & $38(54 \%)$ & $6(6 \%)$ & $4(4 \%)$ & $2(2 \%)$ & $<0,001$ \\
\hline Zachwalanie stosowanego sprzętu & „,najnowocześniejszy laser” & $78(78 \%)$ & $36(51 \%)$ & 0 & $2(2 \%)$ & $2(2 \%)$ & $<0,001^{*}$ \\
\hline $\begin{array}{l}\text { Obietnice/gwarancje } \\
\text { bezpieczeństwa, braku działań } \\
\text { niepożądanych }\end{array}$ & „absolutnie bezpieczny”, ,,bez efektów ubocznych” & $59(59 \%)$ & $17(24 \%)$ & $5(5 \%)$ & $4(4 \%)$ & $2(2 \%)$ & $<0,001$ \\
\hline $\begin{array}{l}\text { Oferowanie promocyjnych cen, } \\
\text { pakietów na zabiegi }\end{array}$ & $\begin{array}{l}\text { „Dla osoby odwiedzającej nasz gabinet pierwszy } \\
\text { raz - rabat } 10 \% \text { oraz dodatkowo miła niespodzianka. } \\
\text { Dla osoby polecającej nasz gabinet - rabat } 20 \% \text { na } \\
\text { jednorazowy zabieg z zakresu medycyny estetycznej } \\
\text { do wykorzystania w dowolnym czasie" }\end{array}$ & $56(56 \%)$ & $37(53 \%)$ & $7(7 \%)$ & $2(2 \%)$ & $1(1 \%)$ & $<0,001$ \\
\hline $\begin{array}{l}\text { Reklamowanie gabinetu na } \\
\text { Facebooku, Twitterze, Google+ }\end{array}$ & $\begin{array}{l}\text { „Dołącz do nas na Facebooku a otrzymasz } 15 \% \text { rabatu } \\
\text { na każdy wybrany zabieg” }\end{array}$ & $55(55 \%)$ & $22(31 \%)$ & $6(6 \%)$ & $2(2 \%)$ & $1(1 \%)$ & $<0,001$ \\
\hline Gwarantowanie efektu & „efekt gwarantowany”, „,stuprocentowa skuteczność” & $51(51 \%)$ & $16(23 \%)$ & $7(7 \%)$ & $6(6 \%)$ & $2(2 \%)$ & $<0,001$ \\
\hline $\begin{array}{l}\text { Obiecywanie efektów } \\
\text { wykraczających poza faktyczny } \\
\text { efekt biologiczny zabiegu }\end{array}$ & $\begin{array}{l}\text { „laser odmieni Twoje życie”, ,będziesz } \\
\text { najpiękniejsza”, ,zyskasz nowych wielbicieli”, } \\
\text { „zwalcz swoją nieśmiałość” }\end{array}$ & $43(43 \%)$ & $14(20 \%)$ & 0 & 0 & 0 & $<0,001^{*}$ \\
\hline $\begin{array}{l}\text { Powoływanie się na media, które } \\
\text { opisywały placówkę, artykuły } \\
\text { w prasie na temat placówki, } \\
\text { chwalenie się udziałem } \\
\text { w programach telewizyjnych, jako } \\
\text { placówka wykonująca zabiegi }\end{array}$ & $\begin{array}{l}\text { „IQ Medica jest dumna mogąc być partnerem } \\
\text { „Gotowych na zmiany” i pomagając zmienić życie } \\
\text { tylu wspaniałym kobietom. Odcinki programu można } \\
\text { obejrzeć na antenie Polsat Cafe, w serwisie Ipla i na } \\
\text { stronie YouTube.” }\end{array}$ & $31(31 \%)$ & $8(11 \%)$ & 0 & 0 & 0 & $<0,001 *$ \\
\hline $\begin{array}{l}\text { Reklamowanie produktów } \\
\text { ze wskazaniem konkretnego } \\
\text { producenta }\end{array}$ & $\begin{array}{l}\text { „Dzięki współpracy z takimi markami jak Skin } \\
\text { Ceuticals, Andre Zagozda oraz Matt Picaut mamy } \\
\text { gwarancję, że Państwa skóra będzie piękna, zdrowa } \\
\text { i wypielegnowana”, ,Współpracujemy z: Environ, } \\
\text { Juvederm Ultra, TriPollar, TEOSYAL, Intraceuticals, } \\
\text { RevitaLash, Organique, Endermologie” }\end{array}$ & $29(29 \%)$ & $14(20 \%)$ & 0 & 0 & 0 & $<0,001^{*}$ \\
\hline $\begin{array}{l}\text { Zachwalanie lekarzy wykonujących } \\
\text { zabiegi }\end{array}$ & $\begin{array}{l}\text { „wybitny specjalista”, ,światowy autorytet”, „,ogromne } \\
\text { doświadczenie” }\end{array}$ & $23(23 \%)$ & $12(17 \%)$ & $7(7 \%)$ & $6(6 \%)$ & $4(4 \%)$ & $<0,001$ \\
\hline $\begin{array}{l}\text { Odwoływanie się do celebrytów, } \\
\text { jako klientów danego gabinetu }\end{array}$ & $\begin{array}{l}\text { „Jak dobrze, że jest dr Maciej (...), bo to on na co } \\
\text { dzień myśli o mojej urodzie. Ja nie muszę! Grażyna } \\
\text { Wolszczak”, ,.,...) Odkryłam klinikę w pogoni za } \\
\text { moim ulubionym doktorem Robertem (...), który dba } \\
\text { o mnie i pilnuje spraw zdrowotno-urodowych } \\
\text { z wielkim zaangażowaniem. Bardzo wam wszystkim } \\
\text { dziękuje i będę zawsze wracać. Katarzyna Dowbor” }\end{array}$ & $12(12 \%)$ & $1(1 \%)$ & 0 & 0 & 0 & $<0,001^{*}$ \\
\hline $\begin{array}{l}\text { Oferowanie kosmetyków lub } \\
\text { innych produktów, które można } \\
\text { zakupić w placówce }\end{array}$ & $\begin{array}{l}\text { „Kosmetyki detaliczne indywidualnie dobrane po } \\
\text { zabiegu, takich firm jak: Thalgo; Comfort Zone; } \\
\text { Avene; Galenic; Clarena; La Roche-Posay; dr Irena } \\
\text { Eris; Pharmaceris; L’Oreal - kosmetyki pielęgnacyjne } \\
\text { do włosów”, , ,oferta >> sprzedaż dermokosmetyków } \\
\text { Filogra - linia Cosmotherapie” }\end{array}$ & $11(11 \%)$ & $11(16 \%)$ & 0 & 0 & 0 & $<0,001^{*}$ \\
\hline $\begin{array}{l}\text { Zawarcie w nazwie placówki } \\
\text { oznaczenia „,klinika” }\end{array}$ & $\begin{array}{l}\text { „Dermex Klinika”, „>> Eliksir<<- Klinika Urody } \\
\text { i SPA” }\end{array}$ & $8(8 \%)$ & $11(16 \%)$ & $1(1 \%)$ & $2(2 \%)$ & $2(2 \%)$ & $<0,001$ \\
\hline $\begin{array}{l}\text { Odwoływanie się do autorytetów - } \\
\text { znanych osób, celebrytów } \\
\text { w odniesieniu do metody }\end{array}$ & $\begin{array}{l}\text { "Obecnie VelaShape jest najpopularniejszym } \\
\text { zabiegiem zwalczającym cellulit, któremu poddają się } \\
\text { gwiazdy światowego formatu, takie jak: Madonna, } \\
\text { Demi Moore, Britney Spears i Kim Kardashian!" }\end{array}$ & $8(8 \%)$ & 0 & 0 & 0 & 0 & $<0,001^{*}$ \\
\hline
\end{tabular}

^ porównano różnice w odsetkach w dwóch grupach, do których przyporządkowano: (1) placówki z zakresu medycyny estetycznej, dermatologii estetycznej i chirurgii estetycznej oraz (2) placówki z zakresu alergologii, ginekologii i kardiologii

* test chi-kwadrat z poprawką Yates'a dla małych grup $(\mathrm{n}<5)$

dla znanych osobistości. Polega ono na tym, że ludzie chcąc się upodobnić do swoich idoli, naśladują ich w działaniu, co jest wykorzystywane przez firmy, odwołujące się do celebrytów w kampaniach reklamowych [11].
Wydaje się, że obecna sytuacja na rynku usług medycyny estetycznej jest częściowo wynikiem niedostosowania prawa i regulacji korporacyjnych do rzeczywistości. Z jednej strony usługi medycyny estetycznej, podobnie jak usługi kosmetyczne opodatkowane są naj- 
wyższą stawką VAT, z drugiej gabinety kosmetyczne mogą bez ograniczeń reklamować swoje usługi, podczas gdy reklama usług lekarskich poddana jest znacznym ograniczeniom (tabela 2). Sprzeczne sygnały płyną również ze strony samego samorządu zawodowego. Kodeks etyki lekarskiej zakazuje reklamy usług medycznych, natomiast izby lekarskie organizują szkolenia z zakresu marketingu medycznego, co może sprawiać wrażenie przyzwolenia samorządu dla stosowania przez lekarzy praktyk marketingowych [12]. Lekarze otrzymują zatem sprzeczne sygnały w tym zakresie i na podstawie przedstawionych wyników wydaje się, że w odróżnieniu od przedstawicieli „tradycyjnych” specjalności, lekarze spod znaku medycyny estetycznej wybierają bardziej agresywne działania marketingowe, które zapewne w ich opinii mają szybciej doprowadzić do sukcesu finansowego w warunkach coraz ostrzejszej konkurencji.

Tabela 2. Zestawienie ulg fiskalnych i restrykcji wobec marketingu dla „tradycyjnych" specjalności medycznych, medycyny estetycznej oraz ustug z zakresu kosmetyki i kosmetologii

\begin{tabular}{l|l|l} 
Dziedzina & $\begin{array}{l}\text { Preferencje państwa } \\
\text { (ulgi fiskalne) }\end{array}$ & $\begin{array}{l}\text { Ograniczenia } \\
\text { marketingu }\end{array}$ \\
\hline $\begin{array}{l}\text { „Tradycyjna" medycyna } \\
\text { prewencyjna } \\
\text { i naprawcza }\end{array}$ & $\begin{array}{l}\text { TAK, zwolnienie } \\
\text { z VAT* }\end{array}$ & TAK, zakaz reklamy \\
\hline $\begin{array}{l}\text { Medycyna estetyczna, } \\
\text { dermatologia } \\
\text { estetyczna, chirurgia } \\
\text { estetyczna }\end{array}$ & NIE, stawka VAT 23\% & TAK, zakaz reklamy \\
\hline $\begin{array}{l}\text { Usługi } \\
\text { kosmetologiczne } \\
\text { i kosmetyczne }\end{array}$ & NIE, stawka VAT 23\% & $\begin{array}{l}\text { NIE, możliwość } \\
\text { reklamy } \\
\text { nieograniczona }\end{array}$ \\
\hline
\end{tabular}

*Korzyść pozorna, choć w założeniu zwolnienie z VAT miało być zapewne wyrazem preferencji fiskalnej państwa dla świadczeń zdrowotnych

\section{Wnioski}

Prawie wszystkie placówki medyczne oferujące usługi z zakresu szeroko rozumianej medycyny estetycznej stosują praktyki marketingowe niezgodne z duchem Ustawy o zawodach lekarza i lekarza dentysty, Ustawy o izbach lekarskich, Kodeksu etyki lekarskiej oraz uchwały Naczelnej Rady Lekarskiej. Najczęściej stosowanymi praktykami marketingowymi jest podawanie nazw handlowych preparatów oraz marek stosowanych urządzeń, zachwalanie skuteczności stosowanych metod, zachwalanie stosowanego sprzętu, oraz obietnice/gwarancje bezpieczeństwa i braku działań niepożądanych. W przypadku „tradycyjnych” specjalności lekarskich praktyki tego typu są stosowane bardzo rzadko i z reguły ograniczają się do zachwalania kompetencji lekarzy.

\section{Piśmiennictwo}

1. Ustawa o zawodach lekarza i lekarza dentysty z dnia 5 grudnia 1996 r. z pózn. zm. Dziennik Ustaw 2011; nr 277: poz.1634.

2. Ustawa o izbach lekarskich z dnia 2 grudnia 2009 r. Dziennik Ustaw 2009; nr 219: poz.1708.

3. Uchwała Nr 18/98/III Naczelnej Rady Lekarskiej z dnia 25 kwietnia 1998 r. w sprawie szczegółowych zasad podawania do publicznej wiadomości informacji o udzielaniu przez lekarzy świadczeń zdrowotnych w ramach indywidualnej praktyki lekarskiej.

4. Kodeks etyki lekarskiej z dnia 2 stycznia 2004 r.: art. 63.

5. Kotler P, Shalowitz J, Stevens R. J: Słowniczek. W: Marketing strategiczny w opiece zdrowotnej. Wolters Kluwer Polska, Warszawa 2011: 651-84.

6. Bukowska-Piestrzyńska A: Działania marketingowe prywatnych zakładów opieki zdrowotnej. W: Finansowanie marketingu w ochronie zdrowia. CeDeWu.pl, Warszawa 2010: 53-107.

7. Bukowska-Piestrzyńska A: Przesłanki stosowania marketingu w usługach zdrowotnych. W: Marketing usług zdrowotnych od budowania wizerunku placówki do zadowolenia klientów. CeDeWu Wydawnictwa Fachowe, Warszawa 2011: 13-48.

8. Czerw A: Kompozycja marketingu - mix usług zdrowotnych w sektorze prywatnym. W: Marketing w ochronie zdrowia. Difin, Warszawa 2010: 47-62.

9. Bukowska-Piestrzyńska A: Zwrócenie uwagi pacjenta. W: Marketing gabinetu stomatologicznego. Czelej, Lublin 2011: 114-33.

10. Ustawa o zakładach opieki zdrowotnej z dnia 30 sierpnia 1991 r. Dziennik Ustaw 1991; nr 91: poz. 408 art.1 ust.2.

11. Niczewski R, Potrzebowski R: Celebryci w ataku. W: Celebryci w ataku. Celebrity effect jako skuteczne narzędzie komunikacji marketingowej. Agora, Warszawa 2010: 15-9.

12. Ośrodek Kształcenia Okręgowej Izby Lekarskiej w Krakowie: Zaproszenie na kurs „Jak przyciągnąć pacjentów, czyli marketing medyczny w pigułce". Galicyjska Gazeta Lekarska 2012; (4): 66.

\section{Finansowanie i konflikt interesów}

Przedstawione badania i przygotowania niniejszej publikacji zostało w całości sfinansowane z własnych środków autorów. Autorzy deklarują niewystępowanie konfliktu interesów w odniesieniu do treści zawartych w niniejszej pracy.

\section{Adres do korespondencji}

prof. UJ dr hab. med. Radosław Śpiewak Zakład Dermatologii Doświadczalnej i Kosmetologii UJ CM

ul. Medyczna 9, 30-688 Kraków

E-mail: spiewak.eu@gmail.com

Data złożenia: 30.01 .2012

Data akceptacji: 28.05 .2012

Data aktualizacji: 30.11 .2012 